\title{
A metodologia da problematização na Escola de Posturas da UFPB: um processo emancipatório na prática da educação gerontológica
}

\section{Methodology of the posture school problem study: an emancipation process in gerontology education practice}

\section{Metodología de la problematización en la escuela de posturas: un proceso de la emancipación en la práctica de la educación gerontológica}

\author{
Bianca Nunes Guedes', Maria Iracema Tabosa da Silva"', Cesar Cavalcanti da Silva'"I
}

\section{RESUMO}

O crescente aumento da população idosa no Brasil despertou o interesse dos profissionais que atuam na promoção da saúde. Entre as modificações que ocorrem nesta fase, as alterações posturais vêm sendo uma das causas mais freqüentes de queixas, devido às complicações e às limitações funcionais que acarretam, restringindo a participação social deste grupo etário. Este estudo tem como objetivos: descrever o processo de educação postural à luz do Método do Arco e analisar a eficácia desta alternativa metodológica problematizadora no processo de educação postural na terceira idade. Pesquisa de natureza qualitativa, exploratória descritiva, realizada entre março/ maio de 2006 na Clínica Escola de Fisioterapia da UFPB, e teve como participantes, dez indivíduos idosos. O material empírico foi obtido através das discussões e grupos focais realizados no decorrer da Oficina Problematizadora e a análise dos dados se deu segundo a perspectiva de Fiorin. A eficácia da Metodologia Problematizadora foi constatada diante da ação transformadora na prática das atividades da vida diária dos participantes, por meio da ausência ou diminuição considerável das dores, melhora da capacidade funcional, sensação de bem-estar físico e mental e pela aquisição do conhecimento construído ativamente entre os sujeitos, estimulando o despertar de uma consciência crítica e reflexiva.

Palavras chave: Aprendizagem baseada em problemas; Gerontologia; Postura.

\section{ABSTRACT}

The rising increase of the elderly population in Brazil has aroused the professionals' interest from the most varied fields especially those working as health professionals. The posture changes, among others in this phase, have been the most common complaint due to the complications and the functional limitations that cause and restricting elderly people's social participation. The objectives of this study: describing the posture education process and at analyzing the effectiveness of the alternative problem study methodology in the third age posture education process. Research of qualitative nature, exploratory descriptive, carried out from march to may of 2006 at the Physiotherapy School Clinic of UFPB with ten elderly participants. The empirical evidence was achieved by means of discussions and focal groups held during the Problem Workshop and the speeches were analyzed under the Fiorin perspective. The effectiveness of the Problem Study Methodology was verified as the changing effects on the participants' daily activities showed the absence or the considerable reduction of pain, improvement in their functional capability and a sense of physical and mental well-being as well as the stimulus to the awakening of a critical and reflective conscience originated in the interaction of the individuals.

Key words: Learning based in problems; Gerontology; Posture.

\footnotetext{
Graduada em Fisioterapia pela UFPB. Especialista em Gerontologia pelo Núcleo de Estudos e Pesquisas da Terceira Idade da UFPB. Mestranda do Programa de PósGraduação em Enfermagem / UFPB, com Área de Concentração em Saúde Pública. E-mail: bianca.guedes@gmail.com

"Enfermeira. Doutora em Enfermagem pela Escola de Enfermagem de Ribeirão Preto/ USP. Docente aposentada do Departamento de Enfermagem da UFPB. E-mail: cemasbr@yahoo.com.br

III Enfermeiro. Doutor em Enfermagem pela Escola de Enfermagem da USP. Docente do Departamento de Enfermagem da UFPB. E-mail: profccs@yahoo.com.br
} 


\section{RESUMEN}

El aumento de la población envejecida en Brasil ha despertado el interés de los profesionales que actúan en la promoción de la salud. Entre los cambios que ocurren en esta fase, las alteraciones de postura han sido una de las causas de las quejas más comunes debido a las complicaciones y a las limitaciones funcionales que causan, restringiendo la participación social de este grupo etario. Este estudio tiene como objetivos: describir el proceso de la educación postural a la luz del método del arco y analizar la eficacia de la alternativa metodológica problematizadora en el proceso de educación postural en la tercera edad. La investigación cualitativa, descriptiva exploratoria, realizada entre marzo/ mayo de 2006 en la Clínica Escuela de Fisioterapia de la UFPB con diez participantes de la tercera edad.

\section{NTRODUÇÃO}

A partir da emergência da velhice como fenômeno social no Brasil e nos demais países em desenvolvimento, foi possível verificar uma maior preocupação dos profissionais das mais diversas formações, sobretudo entre aqueles que promovem a assistência à saúde, em direcionar suas práticas para a atenção às peculiaridades do idoso ${ }^{(1)}$.

Dados demonstram que no Brasil, o número de idosos passou de 3 milhões em 1960, para 7 milhões em 1975 e 14 milhões em 2002 [um aumento de 500\% em quarenta anos] e estima-se que alcançará 32 milhões em $2020^{(2)}$. Segundo a Organização Mundial de Saúde - OMS, até 2025, o Brasil será o sexto país do mundo com o maior número de indivíduos idosos, representando $15 \%$ da população nacional ${ }^{\text {(3) }}$.

Em virtude destas modificações observadas na pirâmide populacional, as doenças próprias do envelhecimento tornam-se relevantes no conjunto da sociedade. A conseqüência dessa dinâmica é uma demanda
El material empírico fue alcanzado por medio de discusiones y grupos focales realizados el Taller Problematizador y los datos fueron analizados según la perspectiva de Fiorin. La eficacia de la metodología Problematizadora fue constatada ante la acción transformadora en la práctica de las actividades da vida diaria de los participantes, por medio de la ausencia o la reducción de dolores, mejora de la capacidad funcional, sensación de bienestar físico y mental, y la adquisición del conocimiento construido activamente entre los sujetos, estimulando el despertar de una conciencia crítica y reflexiva.

Palabras clave: Aprendizaje basado en problemas; Gerontología; Postura.

crescente por serviços de saúde, sendo este, um dos desafios atuais: escassez de recursos para uma demanda crescente. Em geral, as doenças dos idosos são crônicas e múltiplas, perduram por vários anos e exigem acompanhamento constante, cuidados permanentes, medicação contínua, além de exames periódicos ${ }^{(4)}$.

No contexto das diversas limitações que o avançar da idade pode acarretar, sejam de ordem física, mental ou social, a teoria da atividade aborda os aspectos funcionais do indivíduo e envolvem as modificações relacionadas às condições anatômicas, psicológicas e de saúde típicas da velhice, havendo, porém, a permanência das necessidades psicológicas e sociais ${ }^{(5)}$. Assim, compreende-se que há o anseio deste grupo etário em manter a sua participação na sociedade, entretanto, as alterações peculiares da terceira idade restringem essa atuação.

Desse modo, verifica-se, que um dos fatores responsáveis pela exclusão social do idoso, pode ser atribuído à diminuição ou perda 
Guedes BN, Silva MIT, Silva CC. A metodologia da problematização na Escola de Posturas da UFPB: um processo emancipatório na prática da educação gerontológica. Revista Eletrônica de Enfermagem [serial on line] 2007 Mai-Ago; 9(2): 298-314. Available from: URL: http://www.fen.ufg. br/revista/v9/n2/v9n2a02.htm

da funcionalidade relacionada à limitação das condições físicas oriundas das alterações morfo-fisiológicas, pois, estando o indivíduo idoso susceptível às perdas funcionais, as sensações de dependência e de inutilidade influenciarão diretamente na sua autopercepção, enquanto ser social, contribuinte para o progresso do meio em que vive $^{(5)}$.

Nesse sentido, a visão que a sociedade tem da pessoa idosa, deve-se, sobretudo, à forma capitalista e consumista de compreender o mundo, os homens e as suas relações; onde - capital e a produção são extremamente valorizados. Em contrapartida, os idosos, em sua maioria, estão fora do mercado de trabalho, por razões como aposentadoria, falta de oferta de emprego, ou mesmo limitação física ou funcional, ficando, geralmente, à margem de uma sociedade, na qual quem tem participação, oportunidade e reconhecimento é quem se mantém ativo e produtivo ${ }^{(6)}$.

Entre essas modificações que caracterizam o processo de envelhecimento, as alterações posturais vêm sendo uma das causas mais freqüentes de queixas, devido às complicações e às limitações funcionais que acarretam ${ }^{(7) .}$

No que se refere aos aspectos agravantes da perda ou diminuição da capacidade funcional decorrente dos desequilíbrios estáticos, evidencia-se a falta de informações por parte dos idosos, cuidadores e familiares quanto às orientações existentes que minimizam e muitas vezes previnem grande parte dos problemas relacionados à postura, assim como, a escassez de serviços de saúde destinados à assistência voltada às peculiaridades dessa faixa etária; associada à limitada utilização de práticas pedagógicas mais eficazes no processo de educação em saúde (7).

Assim, esta pesquisa se propõe a aproximar a alternativa metodológica problematizadora do Método do Arco ${ }^{(8)}$, do processo de educação postural na terceira idade, ressaltando os limites e possibilidades da eficácia desse método nas ações de saúde e particularmente da fisioterapia, tendo em vista o avanço do processo emancipatório na prática da educação gerontológica e o adensamento de estudos posteriores nessa área.

A Metodologia Problematizadora vem sendo utilizada desde a antiguidade, quando entre as formas pedagógicas adotadas por Sócrates (390 a.C.) já era possível observar características problematizadoras; e o próprio Jesus de Nazareth costumava ensinar através de situações problematizadoras, a exemplo da parábola do Bom Samaritano, no intuito de que os seus ouvintes compreendessem o significado de 'próximo' (9). No entanto, esta abordagem continua sendo considerada uma alternativa metodológica inovadora quando aplicada no processo ensino-aprendizagem atual.

Esta metodologia encontra muitos dos pressupostos de sua prática nas correntes filosóficas fenomenológicas, existencialistas e marxistas. Portanto, apresenta um caráter transformador, na medida em que problematiza o conhecimento adquirido, confrontando-o com a realidade, de modo a verificar como esses conhecimentos podem contribuir para explicar, interpretar ou modificar o mundo que nos cerca, encontrando novas aplicações em todos os setores da vida social ${ }^{(10)}$. 
O Método do Arco de Charles Maguerez adaptado por Bordenave e Pereira ${ }^{(8)}$, utilizado neste estudo é composto de 5 etapas: Observação da realidade, Pontos-Chave, Teorização, Hipóteses de Solução e Aplicação à realidade.

Na primeira etapa, que consiste na Observação da Realidade, o educador conduz os alunos a contemplarem uma situação real ou fictícia, ressaltando as questões a serem estudadas na área de interesse. Neste momento, os alunos expressam suas percepções pessoais, realizando assim, uma leitura sincrética ou ingênua da realidade ${ }^{(8)}$.

A segunda etapa é denominada de Pontos-Chave, pois nela, procura-se identificar as possíveis causas e os maiores determinantes sociais do problema que está sendo estudado. Esta etapa consiste em problematizar, o que consiste em formular o problema (uma questão, uma afirmação ou uma negação) a partir de fatos observados, desde que os observemos como realmente inquietantes, problemáticos, instigantes ou inadequados ${ }^{(9)}$.

A terceira etapa, conhecida como Teorização, implica em construir respostas mais elaboradas para o problema, proporcionando o crescimento mental dos alunos a partir dos questionamentos acerca do que foi observado e fundamentado nos pontoschave, definidos na etapa anterior.

Ao confrontar a Realidade com a sua Teorização, o aluno se vê motivado a passar para uma quarta etapa do arco que consiste na formulação de Hipóteses de Solução, em que serão apresentadas alternativas possíveis para a solução do problema em questão. Nessa fase, a criatividade e a originalidade devem ser bastante estimuladas pelo professor, a fim de que os alunos também despertem para as resoluções ideais do problema, e ao mesmo tempo reflitam sobre a sua viabilidade $e$ aplicabilidade à realidade ${ }^{(8)}$.

Por fim, a quinta etapa é a Aplicação à Realidade. Esta se destina à prática e atuação dos alunos na realidade social e nas situações concretas, a partir da seleção das hipóteses de solução apresentadas na etapa anterior. É a fase que possibilita o intervir, o exercitar, o manejar situações associadas à solução do problema; e complementa que com a aplicação à realidade, não apenas se completa o Arco de Maguerez, mas através dos resultados desta aplicação, poderá sugerir o reiniciar de muitos outros $\operatorname{arcos}^{(9)}$.

Desse modo, pretende-se por meio deste método, proporcionar uma participação ativa dos próprios indivíduos idosos na construção do conhecimento acerca dos desequilíbrios estáticos, numa visão mais contextualizada com a prática das atividades realizadas no cotidiano.

Essas reflexões levaram a formular as seguintes questões norteadoras:

- Em que consiste o processo de educação postural destinado às habilidades de adaptação das atividades da vida diária em idosos, à luz da alternativa metodológica problematizadora do Método do Arco?

- A alternativa da pedagogia problematizadora à luz do Método do Arco é eficaz no processo de educação postural em idosos? 
A partir dessas reflexões, foram elaborados os seguintes objetivos para este estudo:

- Descrever o processo de educação postural à luz do Método do Arco, destinado às habilidades de adaptação das atividades da vida diária em idosos.

- Analisar a eficácia da alternativa metodológica problematizadora do Método do Arco no processo de educação postural na terceira idade.

\section{METODOLOGI A}

Esta pesquisa é de natureza qualitativa e do tipo exploratória descritiva. Foi realizada na Clínica Escola de Fisioterapia da Universidade Federal da Paraíba (UFPB) na cidade de João Pessoa-PB, no setor da Escola de Posturas. Teve como participantes 10 idosos, sendo 8 do sexo feminino e 2 do sexo masculino, com faixa etária entre 60 e 82 anos que apresentavam limitações ou queixas referentes às alterações posturais, porém com independência funcional para a locomoção e que voluntariamente aceitaram participar da pesquisa mediante a assinatura do Termo de Consentimento Livre e Esclarecido.

Durante o desenvolvimento de todas as etapas da pesquisa foram considerados os aspectos éticos conforme a Resolução 196/96 do Conselho Nacional de Saúde, que aprova as diretrizes e normas que regulamentam as pesquisas envolvendo seres humanos ${ }^{(11)}$. Após a aprovação do projeto pelo Comitê de Ética e
Pesquisa do Centro de Ciências da Saúde da UFPB, foi dado início à Oficina Problematizadora: Educação Postural para I dosos à luz do Método do Arco.

A Escola de Posturas que, consiste no cenário desta pesquisa, é um Programa de Extensão do Departamento de Fisioterapia da UFPB que presta serviços à comunidade, disponibilizando um tratamento diferenciado para as algias da coluna vertebral. Na Paraíba, a Escola de Posturas foi iniciada em 1990 pela professora Maria Cláudia Gatto Cardia. Baseiase no modelo precursor denominado Back School [escola das costas] e no Brasil foi introduzido por Knoplich no Hospital do Servidor Público de São Paulo (12).

A Oficina adaptada da Programação da Escola de Posturas da UFPB foi realizada no período de 24 de março a 16 de maio de 2006, em 14 encontros, com duração de duas horas cada, perfazendo um total de 28 horas/aula. Colaboraram na realização desta, nove estagiários da referida Escola.

Iniciada a Oficina Problematizadora (Figura 1), do 1으 ao 6으 encontro foram realizadas atividades teórico-práticas que contemplaram as cinco etapas do Arco, abordando os seguintes temas: avaliação da capacidade funcional, orientações posturais básicas, respiração, anatomia e biomecânica da coluna vertebral e suas principais patologias e alterações. Após o desenvolvimento desses seis primeiros encontros foi realizado o Grupo Focal 1 [ 70 encontro] retomando os temas até então trabalhados. 

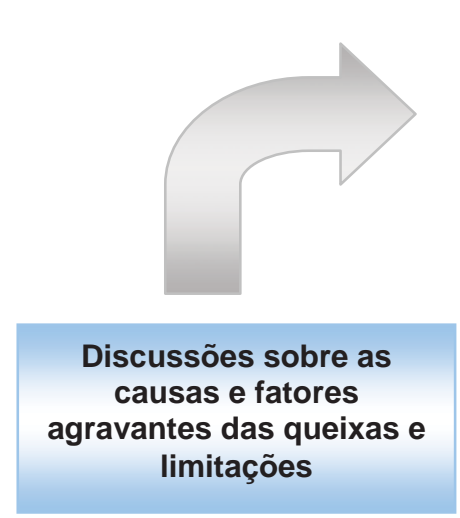

Orientações posturais básicas; sist. respiratório; sist. locomotor I e II; envelhecimento bem-sucedido, alterações posturais na terceira idade; e quedas na pessoa idosa.

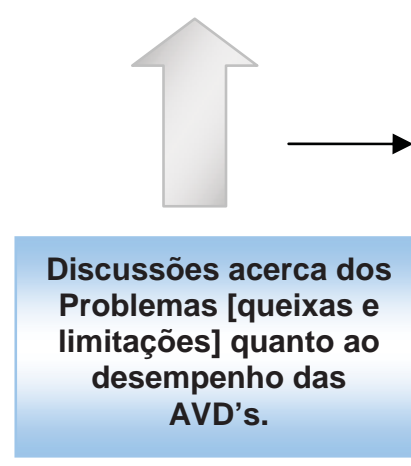

PROBLEMATIZAÇÃO

FUNDAMENTAÇÃO DO CONHECIMENTO

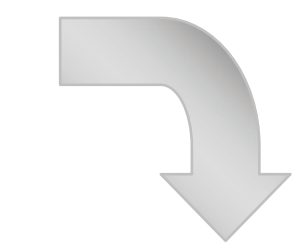

Possibilidades de solução das queixas elou limitações apresentadas pelo grupo.

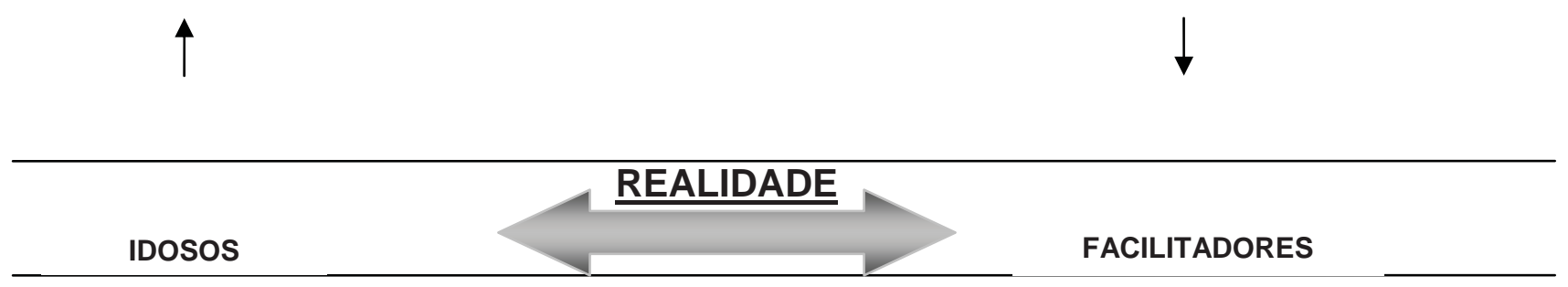

Figura 1: Esquema do Arco desenvolvido na Oficina Problematizadora: educação postural para idosos à luz do Método do Arco

Dado o prosseguimento à realização da programação da Oficina Problematizadora do 8 ao 12 o encontro, foram realizadas atividades teórico-práticas em relação aos seguintes assuntos: anatomia e funcionamento do sistema nervoso voluntário e autônomo; envelhecimento bem sucedido e alterações posturais na terceira idade; marcha, coordenação e equilíbrio; e quedas na pessoa idosa. Na seqüência realizou-se o Grupo Focal 2 [13 encontro] que permitiu contemplar todos os temas trabalhados ao longo da Oficina, incluindo o relato dos participantes sobre a eficácia da mesma no processo de educação postural, fornecendo assim, o respaldo necessário para o alcance do objetivo proposto na pesquisa.

Assim, o material empírico do estudo foi obtido, por meio dos registros das discussões dos grupos focais realizados no 70 e $13^{\circ}$ encontros; sendo também consideradas as discussões ocorridas nos dois primeiros encontros da Oficina.

No âmbito da Saúde, a técnica do grupo focal tem sido útil, devido à maior possibilidade que as atividades focais oferecem se 
Guedes BN, Silva MIT, Silva CC. A metodologia da problematização na Escola de Posturas da UFPB: um processo emancipatório na prática da educação gerontológica. Revista Eletrônica de Enfermagem [serial on line] 2007 Mai-Ago; 9(2): 298-314. Available from: URL: http://www.fen.ufg. br/revista/v9/n2/v9n2a02.htm

comparadas às demais técnicas de pesquisa qualitativa, uma vez que permitem um envolvimento dos participantes nos processos de mudança dos esquemas referenciais e nas atitudes dos seus componentes, adequando-se à proposta da metodologia problematizadora que incentiva a construção ativa do conhecimento ${ }^{(13)}$.

Para a análise e interpretação dos dados coletados, utilizou-se a técnica da análise de discurso proposta por Fiorin. A análise de discurso é indicada nas pesquisas qualitativas, pelas possibilidades de relacionamento dos materiais que envolvem valores, juízos necessários e preferíveis como argumentos que conduzem a um fazer crer relacionado à totalidade do contexto sócio-histórico ${ }^{(14)}$.

A recorrência dos conceitos emitidos pelos participantes através das discussões e dos grupos focais permitiu a visualização de uma série de qualitativos, cujo refinamento, visando ao enxugamento dos temas mais relevantes relacionados ao objeto do estudo, evidenciou A Eficácia da Metodologia Problematizadora no Processo de Educação Postural como Diferencial na Eficiência do Trabalho Fisioterapêutico, tomado como categoria empírica do estudo.

\section{RESULTADOS E DISCUSSÃO}

A Escola de Posturas é uma técnica bastante difundida desde a sua criação em 1969 na Suécia, na área da educação em saúde, devido aos resultados favoráveis na prevenção e cuidados dos problemas da coluna vertebral. Observa-se que não é comum fazer uso de uma abordagem pedagógica de referência para direcionar as atividades realizadas por meio desta técnica, percebe-se, no entanto, um planejamento quanto aos tipos de procedimentos terapêuticos e conteúdos trabalhados, o número de participantes e de sessões, ficando, porém, uma lacuna em relação à abordagem metodológica (15).

Nesse sentido, é importante ressaltar a necessidade de fazer uso de uma abordagem que desenvolva a conscientização dos participantes acerca dos conteúdos e práticas trabalhadas ao longo do programa. Dessa forma, abordagens pedagógicas centradas na práxis libertadora que objetiva uma educação problematizadora e, portanto, conscientizadora, poderão além de instruir e orientar, viabilizar uma prática transformadora capaz de promover uma ação mais eficaz no processo de educação postural.

Diante do exposto, a categoria empírica que direcionará esta discussão discorrerá sobre o domínio da eficácia ao adotar a abordagem problematizadora do Método do Arco na Escola de Posturas, como diferencial na eficiência da intervenção fisioterapêutica.

Para indicação dos discursos dos participantes deste estudo, convencionou-se utilizar a letra "P", seguida de numerações correspondentes a cada indivíduo especificamente.

As etapas da pedagogia problematizadora à luz do Método do Arco serão percorridas ao longo desta análise e discussão, de modo a identificar como os participantes conseguiram interagir com a metodologia adotada na construção do conhecimento para a promoção do auto-cuidado postural.

$O$ enfoque inicial foi dado à motivação para que os participantes procurassem a Escola de Posturas, partindo de uma Observação da 
Realidade inicial em relação à prática das atividades da vida diária [AVD].

Eu consigo fazer tudo em casa, mas sinto dor na região dorso-lombar quando me esforço mais, ou me exercito; eu tenho uma dor em queimação na cervical e lombar e tenho cãimbras nas mãos e também uma forte dor na perna esquerda. Mas eu vim mesmo pra Escola para ter mais conhecimento e preciso de motivação para aplicar esses conhecimentos. (P1)

Eu costumo fazer minhas atividades, mas o que me incomoda são as dores na cervical e na lombar e também tenho osteoporose. Eu procurei a Escola para melhorar das dores. (P3)

Eu consigo fazer algumas atividades em casa e também trabalho, mas sinto dores na coluna e tenho dificuldade pra me abaixar e também tenho bursite. Eu procurei a Escola para ter conhecimentos para melhorar das dores e preciso de estímulo. (P6)

Nestes relatos, a Observação da Realidade, primeira etapa do Método do Arco, foi evidenciada, na medida em que os participantes expressaram suas percepções individuais ao contemplarem uma situação real do próprio cotidiano, relatando suas principais queixas e limitações para a realização das atividades da vida diária, permitindo, ainda, que tivessem uma visão abrangente de tudo que seria abordado ao longo da Oficina a partir da exposição das suas necessidades, isto é, realizassem uma leitura sincrética ou ingênua da realidade, ao perceberem a realidade e descreverem situações que os mesmos vivenciavam $^{(8)}$.

A princípio, os participantes deste estudo identificaram um ou mais fatores que thes causavam incômodos, sendo a dor em regiões da coluna, o principal deles, alguns manifestaram sentir, também, dificuldades para realização de atividades básicas [como andar, levantar e abaixar-se], e mencionaram apresentar patologias [hérnia de disco, bursite, tendinite, escoliose, osteoporose] que podem estar ou não diretamente associadas às dores e/ou às limitações referidas. Em seguida, declararam buscar conhecimento para melhorar das dores, como exemplifica a seguinte afirmação:

Eu procurei a Escola para ter conhecimentos para melhorar das dores e preciso de estímulo (P6); Além de ânimo, motivação e disposição física que foram outros aspectos mencionados como expectativas iniciais ao fazerem parte da Escola de Posturas.

A segunda etapa do Arco, Pontos-Chaves representa uma das razões mais importantes de superação desta pedagogia sobre as de transmissão de conteúdo que, normalmente, atribuem aos facilitadores/professores a tarefa de repassarem os conhecimentos de forma imediata na maioria dos cursos e programas de educação, abrindo pouco ou nenhum espaço para que os usuários manifestem suas idéias, o que acaba por proporcionar um ensino desarticulado com o meio. No entanto, a superação desta etapa consiste em permitir que ocorra a identificação das possíveis causas e fatores associados ao problema, através dos próprios alunos, conduzindo-os à afirmações, questionamentos ou negações, a partir da situação observada.

A seguir, estão expostas as possíveis causas das queixas apresentadas pelos participantes : 
As dores que eu referi que sentia, eu atribuo principalmente à má postura, pois, eu não tinha conhecimento e me posicionava errado, fazia tudo errado. (P1)

Acho que é devido à depressão, o reumatismo e um problema na ciática. (P2)

Eu acho que é por causa do trabalho, pois eu trabalhava muito, pegava muito peso, subia em árvore e caía, lavava muita roupa e fazia muito movimento errado... (P4)

Observa-se que todos os participantes manifestaram opinião a respeito daquilo que poderiam ser as causas das queixas por eles apresentadas, sem que tivessem, necessariamente, plena convicção de suas suposições e nem o conhecimento prévio a respeito do assunto; em função disso, esta etapa tem uma importância fundamental, no sentido de despertá-los para tentarem encontrar a origem dos problemas, partindo deles mesmos o questionamento interior e o direcionamento do foco para o fator causal das dores.

A partir de então, constata-se que as causas referidas vão desde a má postura, excesso de trabalho, fatores de ordem psíquica [depressão], até patologias [como osteoporose, reumatismo e escoliose] e traumas associados.

Do mesmo modo, dando continuidade à etapa dos Pontos-Chaves e visando intensificar a reflexão, os participantes foram, também, levados a expressar o que viam como fatores agravantes das queixas apresentadas.

...O fator agravante é a idade avançada e a falta de exercício físico. (P1)

...A má postura quando sentada e deitada agravam. E acho que o que me afeta muito atualmente é quando eu não corrijo muito os exercícios e a parte mental, pois, quando eu estou chateada ou aborrecida afeta logo a cabeça, a ciática... (P2)

Verifica-se que atividades de maior esforço, alterações relacionadas à idade avançada, problemas emocionais, a má postura e falta de atividades físicas são considerados, pelos participantes, fatores agravantes que contribuem para a manutenção ou intensificação das dores.

Diante dos relatos obtidos, torna-se importante ressaltar que aprender a identificar e controlar as causas e os fatores agravantes das queixas quer sejam físicas ou psíquicas, faz parte das medidas preventivas de autocuidado com a coluna vertebral, uma vez que permite descondicionar posturas e atitudes maléficas para a saúde ${ }^{(7)}$.

A etiologia das dores, em geral, é multifatorial, pois tanto são oriundas de causas físicas como os fatores genéticos, traumas, más posturas, fatores degenerativos decorrentes do processo de envelhecimento; como também, podem ser desencadeadas por causas psíquicas. As algias de coluna podem se manifestar em um ou vários segmentos da coluna vertebral, região cervical, dorsal, lombar ou sacral, e podem ser localizadas ou difusas ${ }^{(12) .}$

Entre as causas físicas mais comuns de dor na coluna estão: má postura [relacionada à maneira de se sentar, de se deitar, de carregar peso], a prática de atividade física excessiva e incorreta, doenças reumáticas [artrite, osteoartrose], processo de degeneração do disco intervertebral [hérnia de disco], patologias compressivas que ocorrem na raiz 
Guedes BN, Silva MIT, Silva CC. A metodologia da problematização na Escola de Posturas da UFPB: um processo emancipatório na prática da educação gerontológica. Revista Eletrônica de Enfermagem [serial on line] 2007 Mai-Ago; 9(2): 298-314. Available from: URL: http://www.fen.ufg.br/revista/v9/n2/v9n2a02.htm

nervosa do forame intervertebral ou em qualquer ponto do trajeto nervoso, rotação de vértebras, esforço muscular, distensões musculares nas costas ou lesões articulares [luxação, ruptura], doenças do trabalho ocasionadas por aumento de carga, sobreuso e esforço repetitivo que podem causar inflamações [tendinites], patologias traumáticas [fraturas], patologias degenerativas [osteoporose, osteofitose], bem como doenças neurológicas periféricas e centrais que afetam os músculos e alteram a postura [distrofias musculares polineurite, paralisias e acidente vascular cerebral] ${ }^{(16)}$.

Em se tratando das causas psíquicas que têm grande importância no tratamento das algias da coluna vertebral, nem sempre elas são responsáveis diretas pela dor, mas geralmente desencadeiam ou são vistas como fatores agravantes dos processos dolorosos através das tensões musculares. As agressões psíquicas advêm da repetição dos problemas cotidianos ocorridos e não resolvidos, nas relações interpessoais, por perdas afetivas, ou, ainda, por razões de mudanças inesperadas. Todos esses fatores podem contribuir para o surgimento de problemas diversos, quer sejam nos ossos, nos discos, nos músculos, como também podem afetar alguns órgãos e outras partes do corpo, uma vez que todas as formas de tensão e bloqueio estão guardadas em algum ponto da coluna, prejudicando a saúde dos órgãos e membros correspondentes ${ }^{(12)}$.

O reumatismo corresponde a uma diversidade de doenças existentes que afetam as articulações, músculos e esqueleto, caracterizado por dor e restrição do movimento. Portanto, o termo não se refere a nenhuma doença específica e sim, a grupo de doenças, o que impede uma definição que abranja adequadamente todas elas, uma vez que os mecanismos causais das patologias e os órgãos atingidos variam bastante ${ }^{(17)}$.

As principais doenças reumáticas são: artrose/osteoartose [sendo esta a doença articular mais freqüente], artrite reumatóide, espondilite anquilosante, gota, o lupus eritematoso sistêmico [doenças do colágeno], osteoporose, febre reumática, fibromialgia reumática, artrite psoriática, polimialgia, tenossinovite, capsulite e bursite. Enumeram como sintomas mais pertinentes: a dor na coluna, febre baixa, perda de peso, cansaço, fraqueza muscular, dificuldade para se levantar ou carregar peso, dores e inchaços articulares, formigamento ou sensação de dormência, dor em repouso que melhora com a movimentação, extremidades frias e arrocheadas com piora no frio, rigidez ou sensação de movimentos presos (17)

As doenças reumáticas são geralmente de origem genética e emocional. Portanto, a prevenção é ter uma boa alimentação, fazer exercícios físicos regularmente e controlar o nível de estresse; sendo assim, caso a doença se manifeste, será de uma forma mais leve e de controle mais fácil ${ }^{(16)}$.

Outra afecção que é causa freqüente de dor na coluna é a escoliose. De modo geral, as causas da escoliose são extremamente variadas e são identificadas cinco, consideradas como principais: as escolioses de adaptação caracterizadas por uma rotação da pelve, um torcicolo, uma perna mais curta, etc. que obrigam a coluna vertebral a colocar-se em uma situação de compensação; as escolioses congênitas - uma vértebra cuneiforme, uma artrodese vertebral, entre outros fatores que 
Guedes BN, Silva MIT, Silva CC. A metodologia da problematização na Escola de Posturas da UFPB: um processo emancipatório na prática da educação gerontológica. Revista Eletrônica de Enfermagem [serial on line] 2007 Mai-Ago; 9(2): 298-314. Available from: URL: http://www.fen.ufg. br/revista/v9/n2/v9n2a02.htm

igualmente levam a coluna a adaptar-se; as escolioses neuromusculares ou antálgicas freqüentemente denominadas falsas escolioses, são devidas à atuação dos mecanismos automáticos de defesa, cujo papel é de esconder a dor, nestes tipos de escoliose, a dor é, na maioria das vezes, de origem lombar ou sacroilíaca; atitudes escolióticas - são tradicionalmente redutíveis em decúbito, provocam inclinação lateral das vértebras, porém sem rotação dos processos espinhosos na concavidade e sem causa dolorosa aparente; e, por fim, as escolioses essenciais ou idiopáticas - sem causa imediatamente aparente, apresentam, portanto, o problema de saber se corresponde a uma patologia em si ou a uma sintomatologia, estas têm origem hereditária multifatorial [as formas familiares podem atingir $43 \%]^{(18) .}$

O desvio lateral da coluna é uma das alterações mais presentes em idosos, e embora seja considerada uma afecção peculiar do crescimento, encontrando nesta fase sua maior incidência, a escoliose pode justapor-se a uma atitude escoliótica na idade adulta e ter a sua intensificação durante a velhice ${ }^{(7)}$.

Contudo, pôde ser observado que as possíveis causas e fatores agravantes das queixas e/ou limitações mencionadas pelo grupo, em geral, tiveram concordância com a literatura consultada, demonstrando que a vivência com o problema possibilita ao indivíduo associar fatores causais independentemente de possuir um diagnóstico confirmado ou conhecimento prévio.

Após a etapa dos Pontos-chaves, segue a Teorização que representa o momento da construção das respostas mais elaboradas para o problema em estudo, ocorrendo a busca do por que, das incidências, interpretações e das relações sobre o objeto da pesquisa (8). Os aspectos registrados como pontos-chaves podem orientar essa busca de informações que podem ser obtidas através das mais variadas fontes.

Essa etapa compreende operações analíticas que são extremamente enriquecedoras, permitindo aos alunos passarem de 'operações concretas' para as 'operações abstratas', proporcionando-lhes poder de generalização e extrapolação, sendo esta outra razão de superação em relação às pedagogias tradicionais ${ }^{(9) \text {. }}$

A etapa de Teorização ocorreu em sete encontros da Oficina, nos momentos de demonstrações práticas e exposições dialogadas acerca dos assuntos abordados em cada unidade da programação da Oficina Problematizadora. Durante o aprofundamento dos conteúdos, foi dada atenção especial ao vocabulário utilizado, a fim de mantê-lo ao nível de compreensão do grupo.

Na elaboração das hipóteses de solução são apresentadas as alternativas possíveis para a resolução do problema em foco e considera que todo estudo desenvolvido até esta quarta etapa deve servir de base para a transformação da realidade ${ }^{(9)}$. Estas elaborações voltam-se para a solução propriamente dita ou para o encaminhamento da mesma, na medida em que o indivíduo busca soluções plausíveis que possam ser implementadas ${ }^{(10)}$.

Diante dos relatos voltados para a elaboração das hipóteses de solução, os 
Guedes BN, Silva MIT, Silva CC. A metodologia da problematização na Escola de Posturas da UFPB: um processo emancipatório na prática da educação gerontológica. Revista Eletrônica de Enfermagem [serial on line] 2007 Mai-Ago; 9(2): 298-314. Available from: URL: http://www.fen.ufg. br/revista/v9/n2/v9n2a02.htm

participantes selecionaram alternativas mais abrangentes, de modo que as pessoas, em geral, possam adotar, como também alternativas específicas, mais direcionadas aos problemas particulares de cada um.

Tudo que foi trabalhado nestes encontros foi muito importante, como a respiração, alongamento, a prevenção das quedas, eu acho que fechou com chave de ouro.. (P3)

$\mathrm{Na}$ minha opinião tudo que aprendi foi muito válido, como por exemplo, os alongamentos e as massagens com a bolinha nas costas! (P6)

A mudança de hábito. Mudar pra corrigir a postura, fazer alongamento e procurar fazer exercício pra melhorar. (P9)

Identifica-se nos trechos citados que todos os participantes, diante das orientações e práticas terapêuticas desenvolvidas no decorrer da oficina, já apresentaram um direcionamento à respeito do que deve ser selecionado como possibilidade de solução para as queixas. Entre as soluções sugeridas, destacam-se: as orientações acerca das posturas corretas, prevenção de quedas e alívio de tensão e estresse, assim como práticas de exercícios, respiração, massagens, alongamentos e relaxamentos.

A atividade física regular e orientada é reconhecida como fator geral na preservação da saúde e na prevenção e controle de doenças de grande expressão na atualidade. Contudo, a manutenção do movimento do corpo é fundamental na busca de preservação da autonomia na idade avançada, em face das perdas fisiológicas próprias do envelhecimento, sendo também relevante a atenção para a consciência corporal e a adoção de certos cuidados posturais na prevenção e controle dos desgastes articulares comuns na velhice ${ }^{(19)}$.
Assim, é indispensável que todos aprendam a perceber melhor o seu corpo e suas funções em relação ao movimento e à posição estática, procurando evitar, por exemplo, posturas flexoras, torções e levantar peso de forma incorreta, pois poderão ocasionar agressões na coluna e nos discos intervertebrais ao sobrecarregar a musculatura e, sabendo disto, o idoso estará orientado a sempre corrigir sua postura, prevenindo a ocorrência de lesões na coluna vertebral ${ }^{(16)}$.

Para desempenhar a maioria das tarefas cotidianas funcionais, como também atividade ocupacional e recreativa é importante apresentar uma amplitude de movimento sem restrições e sem dor, além de uma boa flexibilidade dos tecidos moles que circundam a articulação, ou seja, músculos, tecido conectivo e pele. Sendo assim, o alongamento é uma atividade física bastante indicada na manutenção da mobilidade e flexibilidade dos tecidos moles, sendo definido pelos autores como qualquer manobra terapêutica elaborada para aumentar o comprimento de estruturas de tecidos moles que se encontram encurtadas, contribuindo para aumentar a amplitude de movimentos ${ }^{(19) .}$

A massagem, especialmente a profunda, pode ser usada para aumentar a circulação local ou geral e contribuir na diminuição do espasmo e rigidez muscular. Os efeitos fisiológicos da massagem sobre o organismo podem ser resumidos basicamente em três: calmante, estimulante e desintoxicante ${ }^{(16) .}$

A auto-massagem da coluna com o auxílio da bolinha, desenvolvida por Cardia, baseia-se nos princípios da anti-ginástica de Bérthèrat e consiste em fazer uso da bolinha com o intuito de realizar uma pressão e fricção 
Guedes BN, Silva MIT, Silva CC. A metodologia da problematização na Escola de Posturas da UFPB: um processo emancipatório na prática da educação gerontológica. Revista Eletrônica de Enfermagem [serial on line] 2007 Mai-Ago; 9(2): 298-314. Available from: URL: http://www.fen.ufg. br/revista/v9/n2/v9n2a02.htm

nas inserções musculares dos processos espinhosos transversos, produzindo um efeito de relaxamento muscular ${ }^{(12)}$.

Ao chegar na terceira idade muitos sucessos e fracassos já foram vivenciados e vão constituir o chamado cuidado, na intenção de se preservar o que foi conquistado, e o sentimento de integridade. Isto pode ser expresso na capacidade do indivíduo em rever a sua trajetória de vida e apreciá-la, com algum grau de satisfação, pois a integridade é a marca individual daqueles que conseguem aceitar e conviver com a sua própria trajetória de vida e defender o seu estilo peculiar, que representa o seu patrimônio maior, frente às ameaças e adversidades que a vida possa Ihes reservar ${ }^{(20)}$.

Assim, somente uma personalidade equilibrada, dotada de auto-estima e autoconfiança, poderá fazer frente às demandas e barreiras impostas pelo mundo moderno com sua competitividade e individualismo crescentes, geradores de estresse. As técnicas de relaxamento são instrumentos valiosos que além de permitirem o alívio das tensões, também auxiliam o gerenciamento do estresse e contribuem para desenvolver no indivíduo a capacidade de usufruir a vida com equilíbrio e espontaneidade ${ }^{(19)}$.

Entretanto, antes de iniciar um programa de atividade física, é fundamental que o idoso passe por uma avaliação médica para conhecer melhor sua condição de saúde e os eventuais limites a ela relacionados (17).

Após serem analisadas as possíveis alternativas de solução relatadas pelos participantes, segue-se a Aplicação à Realidade, correspondente à quinta e última etapa do Método do Arco que consiste em aplicar e transferir o que foi aprendido. Através desta fase a realidade será transformada em algum grau com a finalidade de resolver 0 problema identificado na primeira etapa de Observação da Realidade (10).

É importante ressaltar que a etapa da Aplicação à Realidade foi vivenciada tanto durante os encontros da Oficina, no momento de realização das práticas dos procedimentos terapêuticos, quanto no cotidiano dos participantes, ao seguirem as orientações sugeridas e ao executarem os exercícios indicados para o bom desempenho das atividades da vida diária.

Observa-se que foram seguidas as orientações sobre as posturas adequadas para realização das atividades básicas do dia-a-dia, prevenção de quedas e sobre como lidar e controlar o estresse da vida diária. Destaca-se, entre outras, a fala de P1 por não apenas citar as orientações adotadas, mas explicar as razões pelas quais algumas foram colocadas em prática, como forma de aconselhamento por ter partido da experiência particular.

Eu tenho, na medida do possível, tentado aplicar as coisas que tenho aprendido aqui, desde a postura correta de sentar, como me deitar, me levantar, a maneira como pegar um peso e a postura de pendurar roupa no varal. Sigo a orientação sobre prevenção de quedas e sobre a aula de sistema nervoso, no sentido do estresse, já que eu sou muito estressada, tenho procurado me tranqüilizar mais, ser mais calma [...]. Então, vamos ver a realidade, buscando de Deus essa ajuda e também de pessoas que convivem conosco, do que foi ensinado, sempre temos muito que aprender uns com os outros, e assim, vou tentando 
Guedes BN, Silva MIT, Silva CC. A metodologia da problematização na Escola de Posturas da UFPB: um processo emancipatório na prática da educação gerontológica. Revista Eletrônica de Enfermagem [serial on line] 2007 Mai-Ago; 9(2): 298-314. Available from: URL: http://www.fen.ufg. br/revista/v9/n2/v9n2a02.htm

minimizar os meus problemas tanto com o que eu já sabia quanto com o que aprendi aqui. E procurar ter uma vida melhor, com maior qualidade em todos os sentidos, psicológico, físico [...] é assim. (P1)

É fundamental estimular o indivíduo a estabelecer relações, a administrar seu tempo e seu espaço, a criticar e interferir na realidade de modo reflexivo e criativo, a adotar estratégias de solução de problemas, a lutar por valores eleitos como direcionadores das relações ente os homens na vida política e social. A Metodologia Problematizadora é uma das alternativas viáveis para nortear esses propósitos ${ }^{(10)}$.

De fato, a Metodologia Problematizadora parte da realidade e para ela retorna, visando à transformação através da resolução, mesmo que parcial, do problema em foco, possibilitando também a transformação dos indivíduos que participam desse processo educativo (10).

Nesse contexto, por meio dos relatos dos participantes da Oficina, faremos um retorno à Observação da Realidade, após ter sido percorrido todo o Arco, de modo a identificar as possíveis mudanças ocorridas ao longo deste percurso voltado para um enfoque crítico-reflexivo acerca dos problemas posturais.

No que se refere às queixas e aos hábitos apresentados pelos participantes, ressaltam-se quais foram as modificações constatadas.

Uma dor cansada que eu relatei sentir na coluna dorso-lombar, quando eu fazia serviços prolongados, eu não tenho mais sentido, também não sei se é porque eu não venho mais fazendo os serviços de lavar roupa, naquela posição errada que eu fazia. Tudo que estou aprendendo aqui estou praticando e pretendo melhorar mais e mais. (P1)

A dor que eu sentia que era demais até, melhorei, pois, agora levo as pernas pra cima, não quero nem saber! [...] aprendi a ser mais calma e eu tenho procurado melhorar a minha postura, a maneira de dormir, venho tendo mais cuidado pra não cair... e, finalmente, foi tudo válido, muito, muito..(P4)

... Agora costumo flexionar o joelho quando vou apanhar alguma coisa no chão, pois eu não curvava por conta da dor nos joelhos, mas eu estou vendo que flexionando e com os alongamentos as dores estão diminuindo. (P8)

Pôde-se observar que em todos os depoimentos foram expressas mudanças quanto às queixas e às limitações a partir das orientações seguidas, práticas de exercícios, alongamentos e modificações dos hábitos posturais adaptados ao cotidiano do grupo.

Entre as queixas manifestadas no início da Oficina, a dor foi a mais citada pelo seu caráter agravante e limitante, porém ao finalizar o Arco, permitindo realizar uma segunda Observação da Realidade, evidenciam-se, através dos relatos, a ausência ou diminuição significativa da mesma, como também melhora da capacidade funcional daqueles participantes que apresentavam limitação de algum movimento ou função. Aliados aos benefícios alcançados, relatos de sensação de bem-estar e satisfação também foram freqüentes.

Portanto, para consolidar o alcance do objetivo proposto para este estudo, é imprescindível associar ao que já foi exposto, a visão do grupo, a respeito da abordagem metodológica que norteou os caminhos no decorrer desta Oficina, com o intuito de 
Guedes BN, Silva MIT, Silva CC. A metodologia da problematização na Escola de Posturas da UFPB: um processo emancipatório na prática da educação gerontológica. Revista Eletrônica de Enfermagem [serial on line] 2007 Mai-Ago; 9(2): 298-314. Available from: URL: http://www.fen.ufg. br/revista/v9/n2/v9n2a02.htm

possibilitar a análise da sua eficácia no processo de educação postural na terceira idade. Neste sentido, os participantes realizaram as seguintes considerações:

$\mathrm{Na}$ minha opinião foi eficaz demais, foi excelente, foi plena! E é claro que a gente adquiriu novos conhecimentos, a questão da teoria também foi muito importante, até essa troca de informações de um para o outro nos auxiliou demais, então tudo aqui foi maravilhoso, a equipe está de parabéns! [...] O curso foi muito além das minhas expectativas! (P1)

Foi tudo ótimo! Dessa vez foi melhor, porque eu adquiri mais conhecimento do que das outras vezes que eu já tinha freqüentado outros cursos, e a teoria e a prática resplandeceram mais a gente, então foi tudo essencial, tudo muito bom. Achei que os exercícios foram mais novos e achei a turma sempre legal e espero que continue e que divulguem outros cursos. (P2)

Foi demais, foi ótimo mesmo, demais! Tudo nota 10 ! Olhe se fosse possível eu gostaria que tivesse uma manchete de todas as aulas, para colocar naquele vidro ali [mural], porque eu achei importante demais a metodologia,! As minhas expectativas foram correspondidas, e se tiver outro grupo de Escola de Posturas eu vou querer participar pra fixar ainda mais os exercícios, a aula prática, sabe? Foi ótimo demais! (P9)

Em geral, as considerações evidenciaram aspectos como satisfação, autonomia, superação desta Oficina sobre outros cursos e atuação mais participativa do grupo no processo de construção do conhecimento que convergiram para a demonstração da eficácia desta Metodologia.
Ensinar a pensar criticamente exige condições pedagógicas adversas das tradicionalmente utilizadas e para ser alcançado este objetivo é necessário envolver o indivíduo em uma aprendizagem ativa, em situações nas quais ele mesmo seja o responsável por encontrar soluções e tomar decisões, levando-o efetivamente a agir sobre o meio real e a transformá-lo positivamente ${ }^{(9)}$. ...Eu esperava que quando chegasse aqui, seria só a professora ali na frente dando a aula e a gente fazendo os exercícios, mas, na realidade o método é muito melhor, porque está fazendo um levantamento do que sente cada pessoa, como pode fazer pra melhorar e o porquê de estar sentindo estas dores, então achei muito mais proveitoso o curso. (P8)

Este comentário demonstra que a participante reconheceu uma das características fundamentais da Metodologia Problematizadora que consiste na construção ativa do conhecimento estimulado por meio dos questionamentos e atividades práticas adotadas. Identificou, ainda, que o implemento dessa abordagem não se restringe à simples transmissão de informações e orientações, como é comumente observado nos demais espaços nos quais se promovem atividades voltadas para educação em saúde ou mesmo nas instituições de ensino.

Constata-se que através dos conhecimentos construídos e transformações ocorridas em algum aspecto da vida dos participantes, foi efetivado um processo de ensino-aprendizagem com base na estimulação do desenvolvimento de um pensamento crítico e reflexivo. Pensamento este que consiste na combinação de atitudes de questionamentos, 
sustentada através dos conhecimentos e reforçado por uma habilidade em aplicação ${ }^{(10)}$.

Porém, não basta ensinar conteúdos, mas também tem que procurar desenvolver atitudes nos alunos que os levem a investigar, debater, respeitar divergências, organizar-se e tomar decisões coletivamente; além disso, é também responsabilidade dos educadores comprometidos com mudanças, incentivar desafios e rupturas associados aos processos de desconstrução/construção, colaborando, assim, para a superação e instauração do novo (6).

\section{CONCLUSÕES}

No contexto atual do ensino, todas as possibilidades de potencializar a educação nos mais diversos âmbitos aos quais a sua prática se destina merecem ser consideradas. A utilização de abordagens pedagógicas que priorizem inovações, como superações da abordagem tradicional de ensino que apenas reproduz e reforça ideologias e relações dominantes da sociedade, tem sido razão de intensas reflexões e discussões, diante da preocupação em melhor atender às exigências sociais referentes ao processo de ensinoaprendizagem.

Esta pesquisa viabilizou a utilização da abordagem problematizadora ao percorrer as cinco etapas do Método do $\operatorname{Arco}{ }^{(8)}$, a fim de estimular o desenvolvimento do pensamento crítico e reflexivo dos participantes da Escola de Posturas da UFPB, para capacitá-los a realizarem 0 autocuidado postural no desempenho das atividades da vida diária.

A eficácia da Metodologia Problematizadora no processo de educação postural foi constatada diante da ação transformadora na prática das atividades da vida diária dos participantes, retratada por meio da ausência ou diminuição considerável das dores, melhora da capacidade funcional e sensação de bem-estar físico e mental. Associado a todos esses benefícios, a maior confirmação da sua eficácia consistiu na aquisição do conhecimento construído ativamente entre os sujeitos. Essa construção estimulou o despertar de uma consciência crítica e reflexiva, identificada através do aproveitamento e do domínio dos assuntos/habilidades trabalhados, percebida não apenas pela assimilação destes, mas pela capacidade de selecioná-los e aplicá-los de acordo com a real necessidade de cada indivíduo.

Diante do exposto, torna-se evidente que a adoção da abordagem problematizadora no processo de educação postural na terceira idade potencializou a intervenção terapêutica e pedagógica aplicada na Escola de Posturas, podendo ser vista como um diferencial na eficiência do trabalho fisioterapêutico realizado.

Desse modo, a aplicação da metodologia problematizadora que norteou esta pesquisa demonstrou uma possibilidade de atuação inovadora, como alternativa para um ensino tranformador e conscientizador, o que pode vir a estimular e a incentivar outros profissionais a adotarem práticas mais aperfeiçoadas e diferenciadas das tradicionais, sobretudo no meio universitário de onde é originada a força de trabalho, numa perspectiva de formar profissionais mais comprometidos com a realidade social.

Nesse sentido, torna-se necessário repensar sobre a atuação desses profissionais na prestação de serviços destinados à 
promoção e educação em saúde, focalizando os usuários, especialmente os idosos, que também necessitam vivenciar práticas educativas transformadoras que ofereçam efetivamente condições para fomentarem habilidades e competências, a fim de que se tornem sujeitos atuantes na manutenção da própria saúde e da qualidade de vida.

\section{REFERÊNCI AS}

1. Neri AL. Qualidade de vida e idade madura.

5. ed. Campinas: Papirus, 2003.

2. Fundação Instituto brasileiro de Geografia e Estatística. 2000. PNAD (Pesquisa Nacional por Amostra de Domicílio) Acesso e Utilização de Serviços de Saúde 1998. Rio de Janeiro: IBGE.

3. Ravagni E. Sintoma, o mito da idade. Revista do Conselho Regional de Fisioterapia e Terapia Ocupacional, Recife, ano 2, n.5, p.1012, Nov./Dez. 2004.

4. Veras RP. Terceira Idade: Gestão Contemporânea em Saúde. Rio de Janeiro: Relume-Dumará, 2002.

5. Neri AL.Desenvolvimento e Envelhecimento: perspectivas biológicas, psicológicas e sociológicas. Campinas: Papirus, 2001.

6. Santos V, Portella MR, Vieira F. A educação gerontológica: uma reflexão a partir da ótica Freireana. Rev. Téc.-cient. de Enfermagem. v. 2, n.9, p.174-177, 2004.

7. Guedes BN. Avaliação postural em idosos submetidos a um programa especial da Escola de Posturas da UFPB. 2004. 81f. Monografia (Curso de Especialização em Gerontologia, 2) Núcleo de Estudos e Pesquisas da Terceira Idade, Universidade Federal da Paraíba, João Pessoa.

8. Bordenave JD, Pereira AM. Estratégias de Ensino e Aprendizagem. 19. ed. Petrópolis: Vozes, 1998.

9. Berbel NAN. (org.). Metodologia da problematização: uma alternativa metodológica apropriada para o ensino superior. Semina: $\mathrm{Ci}$. Soc/Hum., Londrina, v.16, n.2, p.9-19, out. 1995. Ed. Especial.

10. Tacla MTGM. Desenvolvendo o pensamento crítico no ensino de enfermagem. Goiânia: $A B$, 2002.

11. Brasil. Resolução n. 9196 , de 10 de outubro de 1996. Aprova diretrizes e normas regulamentadoras de pesquisas envolvendo seres humanos. Brasília, DF. Conselho Nacional de Saúde, 1996.

12. Cardia MCG et al. Manual da Escola de Posturas. 3. ed. João Pessoa: Ed. Universitária/UFPB, 2006.

13. Lara MA, Acevedo M, Berenzo S. La depresión femenina vista desde la subjetividad de las mujeres. Cad. de Saúde Pública, v.20, n.3, p.818-828, 2004.

14. Fiorin J L, Savioli FP. Para entender o texto: leitura e redação. 15. ed. São Paulo: Atica, 1999.

15. Andrade SC de, Araújo AGR de, Vilar MJP. Escola de Coluna: revisão histórica e sua aplicação na lombalgia crônica. Rev. Bras. Reumat, São Paulo, v.45, n.4, Jul./Ago. 2005.

16. Reichel $W$ et al. Assistência ao idoso: Aspectos Clínicos do Envelhecimento. 5. ed. Rio de Janeiro: Guanabara Koogan, 2001.

17. Maeda C, Martinez JE, Neder M. Efeito da eutonia no tratamento da fibromialgia. Revista Brasileira de Reumatologia, São Paulo, v.46, n.1, Jan./Feb. 2006

18. Souchar P, Ollier M. As escolioses: seu tratamento fisioterapêutico e ortopédico. São Paulo: Editora é realizações, 2001.

19. Assis $M$ de. Promoção da saúde e envelhecimento: orientações para o desenvolvimento de ações educativas com idosos. Rio de Janeiro: CRDE UnATI UERJ, 2002. Série Livros Eletrônicos Programas de Atenção à Idosos. [cited 2006 ago 19]; Available from: URL: http://www.crdeunati.uerj. br/publicacoes/pdf/promocao_da_sa ude.pdf

20. Penna FB, Santo FH do E. O Movimento das emoções na vida dos idosos: um estudo com um grupo da terceira idade. Revista Eletrônica de Enfermagem [serial on line] 2006 [cited 2007 nov 30]; 8(1): 17-24. Available from: URL:

http://www.fen.ufg. br/revista/revista8_1/origi nal 02.htm

Artigo recebido em 05.12.06

Aprovado para publicação em 27.08.07 